\title{
Herpes-like virus particles in myocardium of patient progressing to congestive cardiomyopathy
}

\author{
PATRICIA J LOWRY, CHRISTOPHER W EDWARDS, ROBERT E NAGLE \\ From the Departments of Cardiovascular Medicine and Pathology, East Birmingham Hospital, Bordesley Green East, \\ Birmingham; and Department of Cardiology, Queen Elizabeth Hospital, Edgbaston, Birmingham
}

SUMMARY A patient presented with myocarditis shortly after contracting chicken-pox and particles with characteristics of the herpes group were found in the myocardial biopsy; subsequently, he progressed clinically and histologically to a cardiomyopathy of the dilated type.

\section{Case report}

A production machinist presented in August 1978 at the age of 25 with a two week history of malaise and lethargy, breathlessness (NYHA 2B), and upper abdominal pain; he had a dry cough, nausea, and vomiting. Ten weeks previously he had been unwell with chicken-pox contracted from his children. At the age of 16 he had chorea, and a heart murmur had been noted earlier in childhood. There was no history of alcohol abuse. Examination showed congestive cardiac failure and moderate mitral regurgitation. The electrocardiogram showed increased left ventricular voltages (S1 V6 $=3.9 \mathrm{mV}$ ), and the chest $x$-ray film confirmed cardiomegaly (cardiothoracic ratio $52 \%$ ). Viral titres including Varicella zoster were negative; Cocksackie titres were not measured. Paul-Bunnell was negative, erythrocyte sedimentation rate was only $1 \mathrm{~mm} / \mathrm{h}$, and the full blood count was normal. In order to determine if the patient had an acute myocardial disease such as myocarditis a right ventricular biopsy was obtained. On light microscopy (Fig. la) most fibres were normal (5 to $12 \mu$ ) but some were swollen to $30 \mu$ and had a "moth-eaten" appearance; there was some karyolysis. No inclusion bodies were seen. On electron microscopy (Fig. 2), small particles were seen approximately 100 $\mathrm{nm}$ in diameter with a hexagonal outer coat and electron dense core-particles resembling viruses of the herpes group. Tissue culture failed to grow an organism.

The patient was treated with digoxin, diuretics, and rest. He was readmitted after nine months for full cardiac catheterisation and repeat biopsy in order to assess progression of the disease. This showed a dilated left ventricle with uniform hypokinesia and moderate mitral regurgitation, an ejection fraction of 0.42 , and end-systolic index of $108 \mathrm{ml} / \mathrm{m}^{2}$. Left ventricular biopsy (Fig. 1b) showed increased interstitial fibrosis and some myofibre degeneration which was not as severe as in the previous biopsy and appeared to represent the healing phase of the myocardial injury. No virus-like particles were seen.

He deteriorated again at the beginning of 1980 , with cough, orthopnoea, malaise, and anorexia, and was reinvestigated in August 1980, when he was found to be in congestive cardiac failure, with a cardiothoracic ratio of $64 \%$. Cardiac catheterisation showed normal coronary arteries, a further reduction in left ventricular function, and severe mitral regurgitation; ejection fraction was 0.35 and end-systolic index $286 \mathrm{ml} / \mathrm{m}^{2}$. Left ventricular biopsy (Fig. 1c) showed extensive cytoplasmic degeneration and an increase in interstitial fibrosis; myofibres were enlarged and nuclei enlarged and irregular.

Despite intensive medical treatment, he remained very limited in exercise capacity (NYHA 3). He was assessed at Papworth Hospital, Cambridge, with a view to cardiac transplantation, but as he had important mitral regurgitation, it was decided to replace his mitral valve in the first instance. At operation, the left ventricle was noted to be dilated and hypertrophied, and the left atrium enlarged: the right ventricle was distended. The mitral valve appeared relatively normal and the cause of the regurgitation was not apparent. Biopsies of the left ventricle confirmed the findings of the biopsy taken in August 1980 (Fig. ld).

After the operation, the patient made a satisfactory recovery and remained clinically improved for two months. Then he deteriorated again (NYHA 4) and a further cardiac catheterisation confirmed a competent 


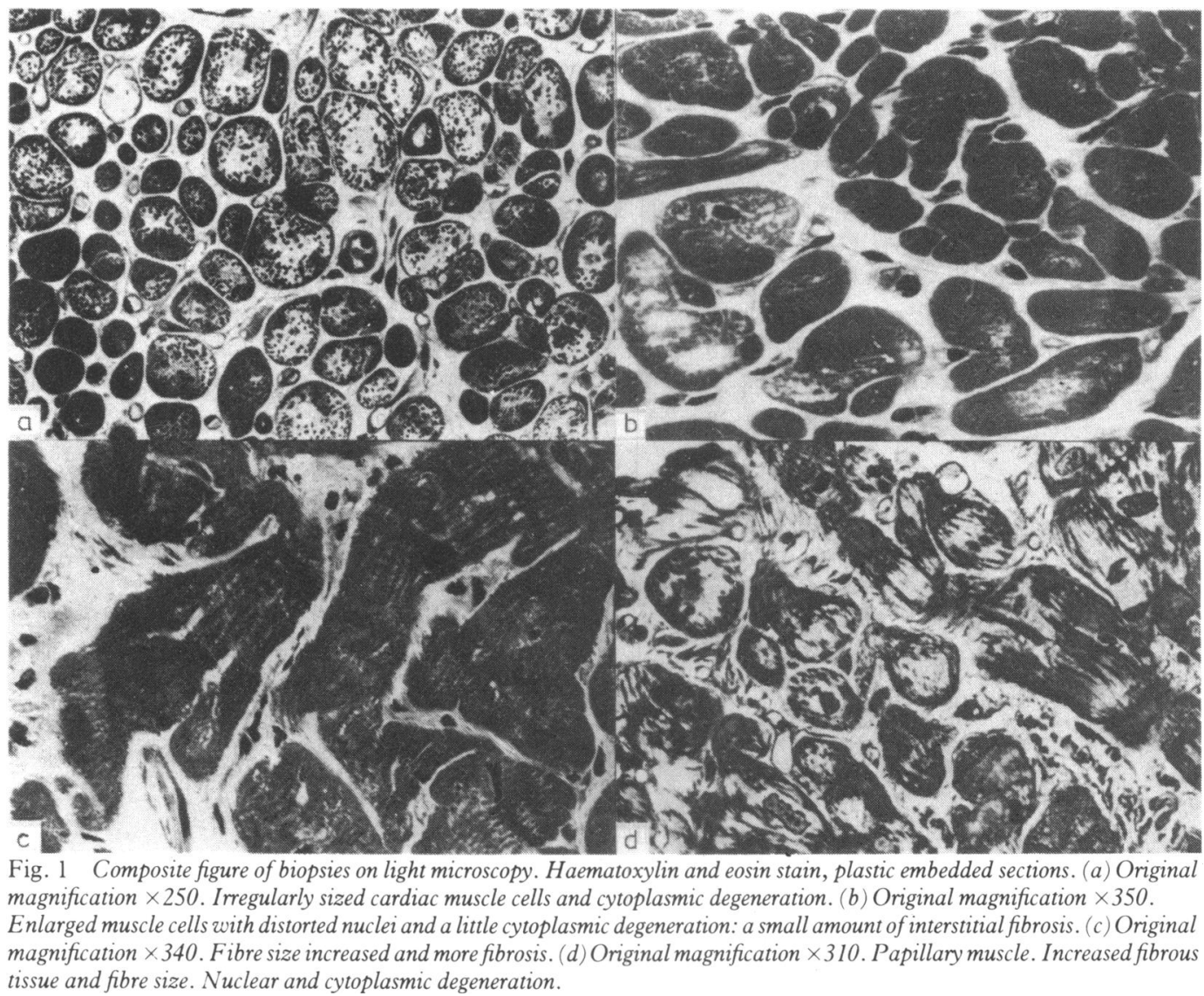

prosthetic valve with extremely poor left ventricular function (ejection fraction 7\%). He underwent cardiac transplantation in June 1981 and is now fully mobile without cardiac symptoms. His own heart weighed 531 $\mathrm{g}$ and the coronary arteries were without stenosis, with only an occasional streak of atheroma. Aortic, tricuspid, and pulmonary valves were normal and the prosthesis was unremarkable. Both ventricles were dilated and the muscle of the left ventricle was of normal thickness $(1 \cdot 3 \mathrm{~cm})$. Histology disclosed some endocardial fibrosis of the left ventricle and a small amount of interstitial fibrosis; muscle fibres were hypertrophied (mean $18 \mu$ ). There was some degenerative change, and a few foci of chronic inflammatory cells. No inclusions were seen.

\section{Discussion}

Our patient presented with the clinical picture of myocarditis shortly after contracting chicken-pox and particles with characteristics of the herpes group were found in the myocardial biopsy; subsequently, he pro- gressed clinically and histologically to a cardiomyopathy of the congestive type.

Congestive cardiomyopathy probably represents a group of diseases with a common end-stage, but different aetiologies. There have been many attempts to show that viral infections initiate a disease process which progresses to congestive cardiomyopathy. ${ }^{1} 2$ Animal experiments ${ }^{34}$ have shown that when mice are infected with Coxsackie $B_{3}$, they develop a severe, acute illness with permanent myocardial damage. The infecting virus can be isolated from the heart in the acute, but not in the chronic, stage. Though myocardial injury is permanent, there is no evidence of congestive cardiac failure. Cambridge et al..$^{5}$ have shown that patients with congestive cardiomyopathy often have high titres of Coxsackie B, especially when the illness started within a year of presentation and where it began with fever. Biopsy of these hearts, however, showed no evidence of myocarditis or virus particles.

Although most cases of viral myocarditis have been attributed to Coxsackie and ECHO viruses, ${ }^{2}$ many other viral infections including varicella ${ }^{6-8}$ have been 


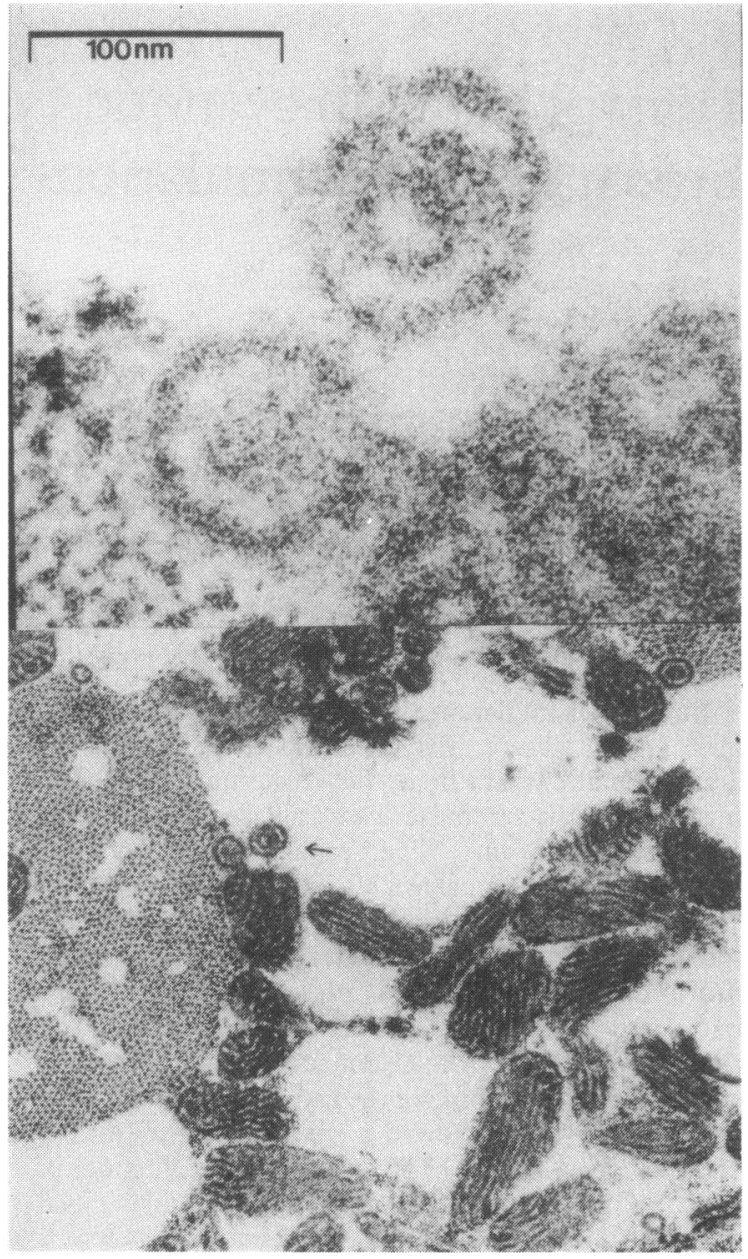

Fig. 2 Electron micrograph, original magnification $4 \cdot 7 \times 10^{4}$. Intracellular oedema, a little myofibrillar degeneration, increased numbers of mitochondria and mitochondrial pleomorphism. Viruslike particles (arrow) at higher magnification $\left(33 \cdot 2 \times 10^{4}\right)$ above.

associated with myocardial damage. Hackel ${ }^{7}$ described varicella myocarditis in six children and one adult who came to necropsy: focal changes were seen in the interstitium and perivascular regions with only occasional muscle fibre necrosis. In the case reported by Tatter $e t$ $a l .{ }^{6}$ there was more extensive myocardial fibre damage. These authors also found intranuclear inclusion bodies in endothelial cells of small blood vessels and in a few myocardial cells.

Most patients with myocarditis recover completely: a few die suddenly, and some progress to a more chronic form of myocardial disease. ${ }^{1}{ }^{10}$ Why this latter group should so progress is not known. Attributing myocarditis to a particular virus can be difficult. ${ }^{2} \mathrm{~A}$ fourfold rise in specific viral antibody titre must be demonstrated, but patients often present too late for the first serological specimen. ${ }^{11}$ Isolation of virus from throat, blood, or stool is hampered by late presentation. Pericardial and myocardial isolation is difficult in life.

This case presented as an acute cardiac illness which on biopsy proved to be a myocarditis. Antibody titre to varicella was not raised, and a pathogenic organism was not grown from an endomyocardial biopsy. The presence of herpes-like particles in the myocardium does not prove that these caused the myocarditis. In addition, it is possible that the patient's heart had been previously damaged by rheumatic fever at the age of 16 though this was not the histological picture of rheumatic heart disease. We postulate that varicella may have been the cause of the initial acute illness affecting the heart, which then progressed to a chronic cardiomyopathy of the congestive type.

We are grateful to Mr T A H English and Dr P G I Stovin, Papworth Hospital, Cambridge for their assistance.

Dr P J Lowry was supported by a British Heart Foundation grant.

\section{References}

1 Somerville W. Postcarditic myocardiopathy. Postgrad Med F 1972; 48: 746-9.

2 Abelmann WH. Viral myocarditis and its sequelae. Annu Rev Med 1973; 24: 145-52.

3 Wilson FM, Miranda QR, Chason JL, Lerner AM. Residual pathologic changes following murine Coxsackie A and B myocarditis. Am F Pathol 1969; 55: 253-65.

4 Kawai C, Takatsu T. Clinical and experimental studies on cardiomyopathy. N Englf Med 1975; 293: 592-7.

5 Cambridge G, MacArthur CGC, Waterson AP, Goodwin JF, Oakley CM. Antibodies to Coxsackie B viruses in congestive cardiomyopathy. Br Heart $\mathcal{F} 1979 ; 41$ : 692-6.

6 Tatter D, Gerard PW, Silverman AH, Wang C-I, Pearson HE. Fatal varicella pancarditis in a child. $A m \mathcal{F}$ Dis Child 1964; 108: 88-93.

7 Hackel DB. Myocarditis in association with varicella. Am f Pathol 1953; 29: 369-76.

8 Thandroyen FT, Asmal AC, Armstrong TG. Varicella myocarditis producing congestive cardiomyopathy. Postgrad Med F 1981; 57: 199-201.

9 Sainani GS ₹rompotic E, Slodki SJ. Adult heart disease due to the Coxsackie virus $\mathrm{B}$ infection. Medicine (Baltimore) 1968; 47: 133-47.

10 Levi GF, Proto C, Quadri A, Ratti S. Coxsackie virus heart disease and cardiomyopathy. Am Heart 7 1977; 93: 419-21.

11 Grist NR, Bell EJ. A 6 year study of Coxsackie virus B infections in heart disease. $\mathcal{F}$ Hyg (Camb) 1974; 73: 16572.

Requests for reprints to Dr P J Lowry, Department of Cardiovascular Medicine, East Birmingham Hospital, Bordesley Green East, Birmingham B9 5ST. 